Journal of Mathematics and Statistics 5 (2): 93-96, 2009

ISSN 1549-3644

(C) 2009 Science Publications

\title{
Efficiency of Differential Transformation Method for Genesio System
}

\author{
Jafar Husni Ahmad \\ Department of Mathematics, Jerash Private University, Jordan
}

\begin{abstract}
Problem statement: In this study, a continuous solution for Genesio system was considered using Differential Transformation Method (DTM). Approach: Numerical results were compared to those obtained by the Runge-Kutta method to evaluate the performance of the suggested method. Results: The accuracy of the DTM was tested as the chaotic Genesio system. Conclusion/Recommendations: It was shown that the DTM was robust, accurate and easy to apply and gave analytical solution on each subinterval, which was not possible in the purely numerical method.
\end{abstract}

Key words: Genesio system, differential transformation, Runge-Kutta, numerical method

\section{INTRODUCTION}

Differential equations have been the focus of many studies due to their frequent appearance in various applications in fluid mechanics, viscoelasticity, biology, physics and engineering. In recent years, much attention has been devoted to the newly developed methods to construct an analytic solutions of nonlinear equation, such methods include the Adomian decomposition method ${ }^{[2,3,5,6]}$ and the Variational Iteration Method (VIM) ${ }^{[6-8]}$, the homotopy analysis method and the homotopy-perturbation method ${ }^{[9]}$ and homotopy analysis method ${ }^{[9-11]}$.

The concept of the Differential Transformation Method (DTM) has been introduced to solve linear and nonlinear initial value problems in electric circuit analysis $^{[1]}$. DTM is a semi-numerical-analytic technique that formalizes the Taylor series in a totally different manner. With this method, the given differential equation and related initial conditions are transformed into a recurrence equation that finally leads to the solution of a system of algebraic equations as coefficients of a power series solution. This method is useful for obtaining exact and approximate solutions of linear and nonlinear differential equations. There is no need for linearization or perturbations, large computational work and round-off errors are avoided. In resent year many researchers apply the DTM for solving differential equation ${ }^{[14,15]}$.

The solution of Genesio system was considered by different researchers such as Goh et al. ${ }^{[12]}$ used VIM to solve the system until time span 10 and Bataineh et $a l .{ }^{[13]}$ obtained the solution using homotopy analysis method for time span 2. Consider Genesio system in the form:

$$
\frac{\mathrm{dx}(\mathrm{t})}{\mathrm{dt}}=\mathrm{y}(\mathrm{t})
$$

$\frac{d y(t)}{d t}=z(t)$

$\frac{d z(t)}{d t}=-c x(t)-b y(t)-a z(t)+x^{2}(t)$

Subject the initial conditions:

$\mathrm{x}(0)=0,2, \mathrm{y}(0)=-0.3, \mathrm{z}(0)=0.1$

where, $\mathrm{a}, \mathrm{b}$ and $\mathrm{c}$ are positive constants, satisfying $\mathrm{ab}<\mathrm{c}$.

In this study, we introduce for the first time an algorithm depending on DTM to solve the Genesio system. Furthermore, we use fourth-order RungeKutta method to demonstrate the efficiency and effectiveness of the proposed algorithm. The results obtained are presented graphically and are found to be in excellent agreement with the numerical solutions. Comparing between the new solution and the solution in $^{[12,13]}$ then new solution is effected for longer time span with less error.

\section{MATERIALS AND METHODS}

To solve Genesio system via DTM we need to take the differential transform of Eq. 1 and 3 with respect to time $t$ gives:

$\mathrm{X}(\mathrm{k}+1)=\frac{\mathrm{H}}{\mathrm{k}+1} \mathrm{Y}(\mathrm{k})$ 
$\mathrm{Y}(\mathrm{k}+1)=\frac{\mathrm{H}}{\mathrm{k}+1} \mathrm{Z}(\mathrm{k})$

$$
\mathrm{Z}(\mathrm{k}+1)=\frac{\mathrm{H}}{\mathrm{k}+1}\left[\begin{array}{l}
-\mathrm{cX}(\mathrm{k})-\mathrm{bY}(\mathrm{k})-\mathrm{aZ}(\mathrm{k}) \\
+\sum_{\mathrm{i}=0}^{\mathrm{k}} \mathrm{X}(\mathrm{i}) \mathrm{X}(\mathrm{k}-\mathrm{i})
\end{array}\right]
$$

where, $\mathrm{X}(\mathrm{k}), \mathrm{Y}(\mathrm{k})$ and $\mathrm{Z}(\mathrm{k})$ are the differential transformations of the corresponding functions $\mathrm{x}(\mathrm{t}), \mathrm{y}(\mathrm{t})$ and $\mathrm{z}(\mathrm{t})$, respectively and the initial conditions are given by $\mathrm{X}(0)=0.2, \mathrm{Y}(0)=-0.3$ and $\mathrm{Z}(0)=0.1$. The difference equations presented in Eq. 5-7 describe the Genesio system, from a process of inverse differential transformation, i.e.:

$$
\begin{aligned}
& x_{i}(t)=\sum_{k=0}^{n}\left(\frac{t}{H_{i}}\right)^{k} X_{i}(k), 0 \leq t \leq H_{i} \\
& y_{i}(t)=\sum_{k=0}^{n}\left(\frac{t}{H_{i}}\right)^{k} Y_{i}(k), 0 \leq t \leq H_{i} \\
& z_{i}(t)=\sum_{k=0}^{n}\left(\frac{t}{H_{i}}\right)^{k} Z_{i}(k), 0 \leq t \leq H_{i}
\end{aligned}
$$

where, $\mathrm{k}=0,1,2, \mathrm{n}$ represents the number of terms of the power series, $\mathrm{i}=0,1,2$, expresses the $\mathrm{i}$-th subdomain and $\mathrm{Hi}$ is the sub-domain interval.

\section{RESULTS AND DISCUSSION}

The accuracy of the DTM is demonstrated against Maples built-in fourth-order Runge Kutta procedure $\mathrm{Rk} 4$ for the solutions of chaotic system. The number of significant digits is set to be 16 in all the calculations. We set $\mathrm{a}=1.2, \mathrm{~b}=2.92$ and $\mathrm{c}=6$, the domain divided using $4 \mathrm{t}=0.01$ comparing with $\mathrm{Rk} 4$ with step size $\mathrm{h}=0.001$. Figure 1 present the comparison between DTM solution and Rk4 solution we can see the good agreement for DTM solution with Rk4 solution. The phase portray of the Genesio system is given in Fig. 2, it is clear that this is chaotic attractor for Genesio system.

The difference between 5-term DTM with $\Delta \mathrm{t}=0.01$ and Rk4 with $\mathrm{h}=0.001$ are given in Fig. 3 . Figure 3 shown that the DTM have higher accuracy of the solution since in the $\mathrm{x}$ and $\mathrm{y}$ axis we have error until $10^{-5}$ (i.e., the solution via the new method has agreement with the purely numerical until 5 digit).

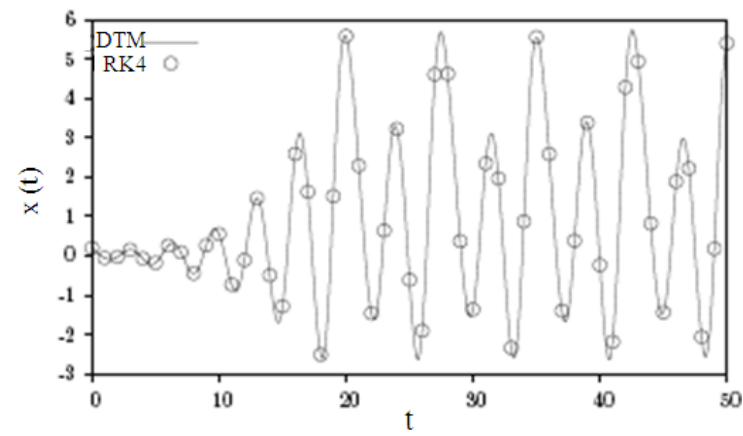

(a)

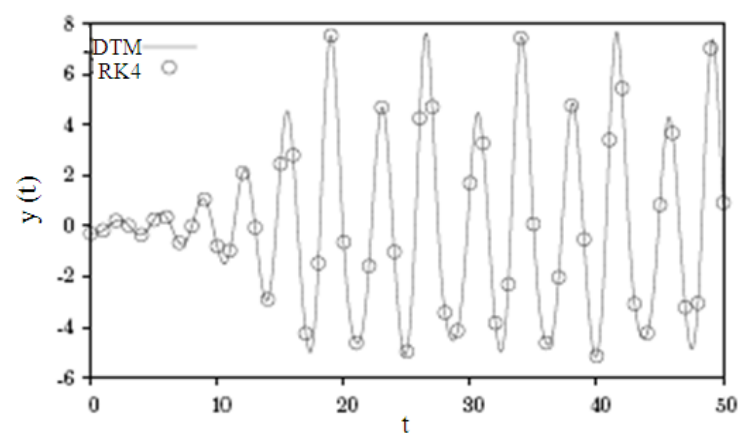

(b)

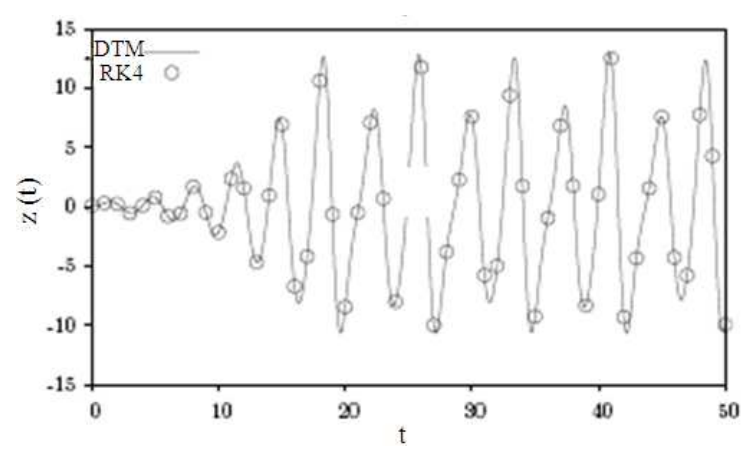

(c)

Fig. 1: The DTM solution comparing with RK4

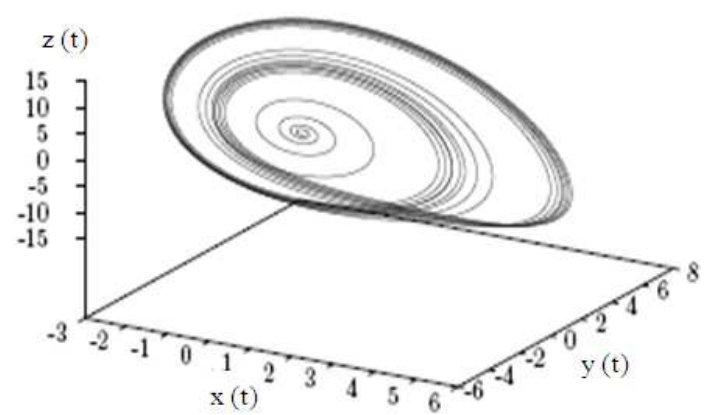

Fig. 2: Phase portray for Genesio system with time span $[0,70]$ using DTM 


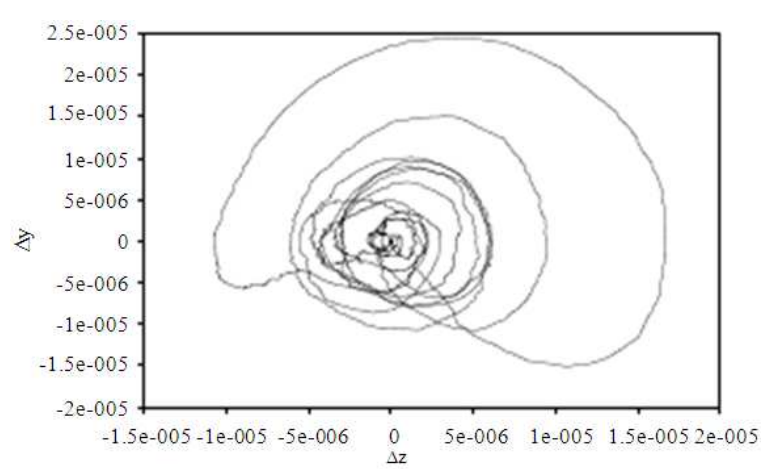

(a)

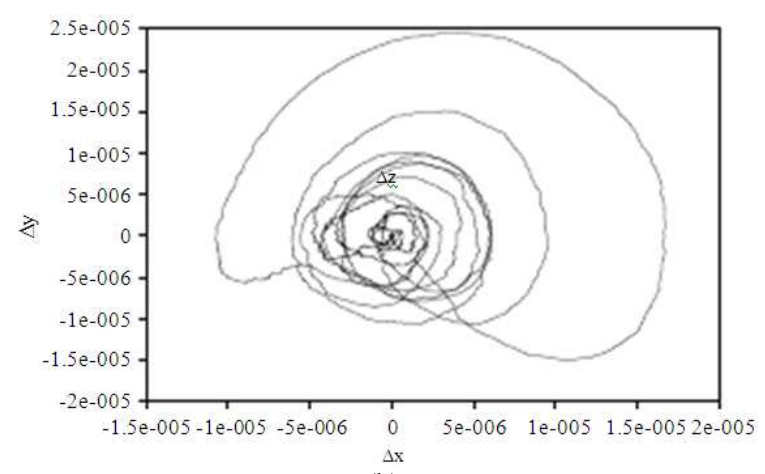

(b)

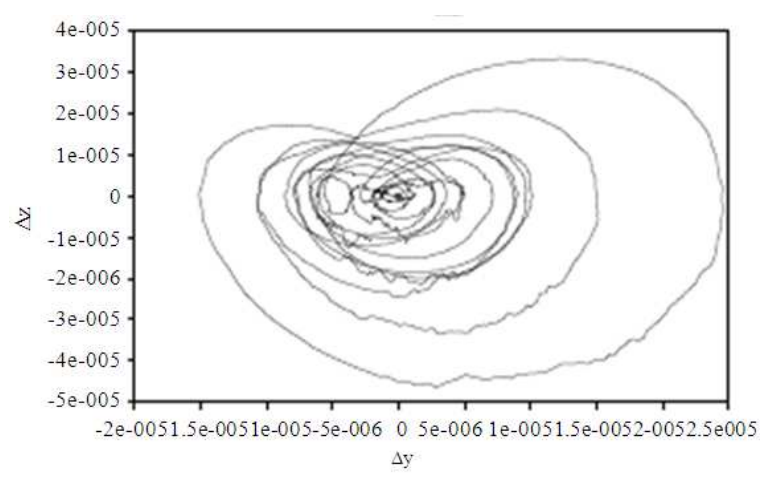

(c)

Fig. 3: Difference between 5-term DTM with $\Delta \mathrm{t}=0.01$ and $\mathrm{Rk} 4$ with $\mathrm{h}=0.001$

\section{CONCLUSION}

In this study, an algorithm for solving Genesio chaotic system was introduced via DTM. Higher accuracy solution was obtained via this algorithm. Comparison between DTM solution and $\mathrm{Rk} 4$ solution is discussed and plotted. The solution via DTM is continuous on this domain and analytical at each subdomain which is the best in our knowledge.

\section{REFERENCES}

1. Zhou, J.K., 1986. Differential Transformation and its Applications for Electrical Circuits, Huazhong University Press, Wuhan, China. (In Chinese). http://scitation.aip.org/getabs/servlet/GetabsServlet ?prog=normal\&id=JHTRAO000124000001000208 $000001 \&$ idtype $=$ cvips \&gifs $=$ yes

2. Hashim, I., Adomian decomposition method for solving BVPs for fourth-order integro-differential equations. J. Comput. Applied Math., 193: 658-664. DOI: 10.1016/j.cam.2005.05.034

3. Hashim, I., M.S.M. Noorani, R. Ahmad, S.A. Bakar, E.S.I. Ismail and A.M. Zakaria, 2006. Accuracy of the Adomian decomposition method applied to the Lorenz system. Chaos Soliton Fract., 28: 1149-1158. DOI: 10.1016/j.chaos.2005.08.135

4. Noorani, M.S.M., I. Hashim, R. Ahmad, S.A. Bakar, E.S.I. Ismail and A.M. Zakaria, 2007. Comparing numerical methods for the solutions of the Chen system. Chaos Soliton Fract., 32: 1296-1304. DOI: 10.1016/j.chaos.2005.12.036

5. Al-Sawalha, M.M., M.S.M. Noorani and I. Hashim, 2007. On accuracy of Adomian decomposition method for hyper-chaotic Ro ssler system, Chaos Soliton Fract. (In press).

http://www.sciencedirect.com.ezlibrary.ju.edu.jo/sci ence?_ob=MImg\&_imagekey=B6TJ4-4R2Y45X-3$9 \&$ _cdi $=5300 \&$ \&user $=1762376 \&$ \&orig $=$ search $\&$ _co verDate $=11 \% 2$ F07\%2F2007\&_sk=999999999\&vie $\mathrm{w}=\mathrm{c} \& \mathrm{wchp}=\mathrm{dGLbVzz}-$

zSkzV\&md5=e2936203113431b0753b004851a3c9 4b\&ie=/sdarticle.pdf

6. Batiha, B., M.S.M. Noorani and I. Hashim, 2007. Numerical solution of sine-Gordon equation by variational iteration method. Phys. Lett. A., 370: 437-440. DOI: org/10.1016/j.physleta. 2007.05.087

7. Batiha, B., M.S.M. Noorani and I. Hashim, 2007. Variational iteration method for solving multispecies Lotka Volterra equations. Comput. Math. Appli., 54: 903-909. DOI: org/10.1016/j.camwa.2006.12.058

8. Batiha, B., M.S.M. Noorani and I. Hashim, 2007. Application of variation iteration method to heat and wave-like equations. Phys. Lett. A., 369: 55-61. DOI: org/10.1016/j.physleta.2007.04.069

9. Chowdhury, M.S.H. and I. Hashim, 2007. Application of multistage homotopy-perturbation method for the solutions of the Chen system. Nonlinear Anal.: Real World Appli., 10: 381-391. DOI: 10.1016/j.nonrwa.2007.09.014 
10. Liao, S.J., 2003. Beyond Perturbation: Introduction to Homotopy Analysis Method. 1st Edn., Chapman and Hall/ CRC Press, Boca Raton, ISBN: 10: $158488407 \mathrm{X}, \mathrm{pp}: 336$.

11. Alomari, A.K., M.S.M. Noorani and R. Nazar, 2008. Adaptation of homotopy analysis method for the numeric-analytic solution of Chen system. Commun. Nonlinear Sci. Numer. Simul., 14: 1346-1354. DOI: 10.1016/j.cnsns.2008.02.007

12. Goh, S.M., M.S.M. Noorani and I. Hashim, 2007. Efficacy of variational iteration method for chaotic Genesio system classical and multistage approach. Chaos Soliton Fract. DOI : 10.1016/j.chaos.2007.10.003

13. Bataineh, A.S., M.S.M. Noorani and I. Hashim, 2008. Solving systems of ODEs by homotopy analysis method. Commun. Nonlinear Sci. Numer, Simul., 13: 2060-2070.

http://www.elsevier.com/wps/find/journaldescripti on.cws_home/622724/description\#description
14. Abdel-Halim Hassan, I.H., 2004. Differential transformation technique for solving higher-order initial value problems. Applied Math. Comput., 154: 299-311. http://www.elsevier.com/wps/find/journaldescripti on.cws_home/505613/description\#description

15. Ayaz, F., 2004. Solution of the system of differential equations by differential transform method. Applied Math. Comput., 147: 54767. http://www.elsevier.com/wps/find/journaldescripti on.cws_home/505613/description\#description 